\title{
Poor Medication Adherence, Being Unemployed and Substance Use as Correlates of Suicidal Plan in Diabetes Mellitus Patients, 2020
}

\author{
Mogesie Necho*, Mekonnen Tsehay, Asmare Belete \\ Department of Psychiatry, College of Medicine and Health Sciences, Wollo University, Dessie, Ethiopia \\ Email address: \\ nechomoges2014@gmail.com (M. Necho),jimma1760@gmail.com (M. Tsehay), yasmarebel@yahoo.com (A. Belete) \\ ${ }^{*}$ Corresponding author
}

To cite this article:

Mogesie Necho, Mekonnen Tsehay, Asmare Belete. Poor Medication Adherence, Being Unemployed and Substance Use as Correlates of Suicidal Plan in Diabetes Mellitus Patients, 2020. American Journal of Psychiatry and Neuroscience. Vol. 8, No. 3, 2020 , pp. $40-45$. doi: 10.11648/j.ajpn.20200803.11

Received: April 29, 2020; Accepted: May 26, 2020; Published: August 10, 2020

\begin{abstract}
BACKGROUND: Suicidal behaviors are parts of the course of diabetes due to multiple burdens diabetes imposes on patient's life. However, these areas are not well researched. So we assessed suicidal plan and the associated risk factors among Diabetes Mellitus patients in this study. METHOD: Institution based cross-sectional study was conducted in May, 2017. A pre tested, structured and standardized questionnaire was used to collect data. Systematic sampling was used to recruit 421 participants. Binary logistic regression was employed to identify factors associated with outcomes. Odds ratio with $95 \% \mathrm{CI}$ was computed and variables with a p-value of $<0.05$ in the final binary logistic regression model were declared as statistically significant predictors of suicidal plan. RESULTS: Four hundred twenty one patients included in our study with $96.3 \%$ response rate. Average age of the respondents was $38.0( \pm 13.9)$ years. The prevalence suicidal plan was $10.7 \%$. Final regression model showed that being unemployed $(\mathrm{AOR}=3.59,95 \% \mathrm{CI}: 1.25,10.89)$, poor medication adherence $(\mathrm{AOR}=2.43,95 \% \mathrm{CI}: 1.83,8.15)$ and current use of substance $(\mathrm{AOR}=1.82,95 \% \mathrm{CI}(1.45,4.24)$ were associated factors for suicidal plan. CONCLUSION: This study reached at a point that suicidal plan was high in diabetic patients. Being unemployed, poor medication adherence and current use of substance were associated factors for suicidal plan. Due consideration should be given for such public health issue in diabetes patients.
\end{abstract}

Keywords: Suicide, Diabetes Mellitus, Metabolic Syndrome, Ethiopia

\section{Introduction}

Diabetes mellitus which is basically a disorder in the metabolism of carbohydrates and lipids due to either decreased insulin secretion or increased insulin resistance become a major public health challenge nowadays [1]. Global statistics indicates millions of people across the world are affected by this illness and by the year 2013 there were 382 million people living with diabetes mellitus s (DM) and projections estimated that 592 million people will be affected by $2035[2,3]$ in which the great majority resides in low and middle-income countries.

Since diabetes mellitus is psychologically demanding chronic medical condition $[4,5]$ due to the complexity of its pathophysiology and chronicity of treatment, psychiatric disorders are highly prevalent; might reach $84 \%$ and $80 \%$ for mood disorders and anxiety disorders respectively [6, 7]. Suicidality which represents behavioral spectrum with severity ranging from thoughts of death, to suicidal ideation, plan, intent, suicidal attempts and completed suicide [8] is also higher among DM patients $[9,10]$ than the general population. Despite the fact that the bidirectional association between diabetes and depression had long been recognized [7, 11-13], there is un-clarity among relationship of diabetes and suicide risk [11, 14, 15] but depression might have a mediating role in the association between DM and suicide [11].

Based on data from World Health Organization (WHO) 50\% of all violent deaths in men and $71 \%$ in women is due to suicide and the 2nd leading cause of death in 15-29-year age group 
worldwide (16) is also suicide. More than two-third (85\%) of the global suicides statistics is from low and middle-income countries (LMICS), of which 34,000 occur in Africa per year [17]. In Ethiopia $6.3 \%$ of the population is affected by non-fatal suicidal behavior [18]. Suicidal attempt among people with DM had been reported as high as $58.5 \%$ [19] in the USA which is higher than the prevalence in the general population (1.1 to 4.6\%). Studies showed that suicidal plan was 9.7\% [10], 13.5\% [9] in two USA studies.

Suicidal behaviors in DM was significantly associated with lower than high school education and female gender in USA [20], alcohol use and cigarette smoking in USA [9], depression in USA [9], South Korea [21], Brazil [10], duration of illness longer than 5 years and medication non adherence in two USA studies $[19,22]$.

The impacts of suicide are not only loss of life, but the mental, physical and emotional stress imposed on family members and costs to resources, as people with attempted suicide often require help from health care and psychiatric institutes [8]. Prior suicide attempts are one of the strongest predictors of completed suicide [23, 24], suggesting that suicidal behaviors like ideation, plans and attempts as useful outcomes to study.

Even though, suicidal plan are common conditions affecting quality of life of patients in diabetes mellitus in low income countries including Ethiopia, less emphasis is given for them. So this study assessed the prevalence and correlates of suicidal plan among diabetes mellitus patients in the study setting.

\section{Materials and methods}

\subsection{Study Setting}

This analytical cross sectional study was conducted over a one month period from May to June 21, 2017at Felegehiwot referral hospital diabetic outpatient clinic with an approximate distance of $578 \mathrm{~km}$ from Addis Ababa (capital city of Ethiopia) in the northwest direction. Data from census conducted by central statistical agency of Ethiopia in 2007 found that the catchment population of Bahirdar city was 221,991 [25] and Felehehiwot referral hospital serves as referral setting for more than 5.5 million people. On average one thousand three hundred eighty four (1384) diabetic patients had follow up visit monthly in the diabetic clinic of the hospital.

\subsection{Sample Size Determination, Techniques and Procedures}

The sample size for the study was calculated using single population proportion formula, considering a prevalence of $50 \%$ for suicidal plan, $5 \%$ margin of error, $95 \%$ confidence level and $10 \%$ non-response rate. The final estimated sample size was 423 . The sampling interval was computed by dividing the estimated number of patients with follow up per month to the sample size (1384/423) and was 3. The first patient was selected using a lottery method and every third of follow up patients were recruited till final sample size was achieved. All adult diabetic patients aged 18 years and older who attend with follow up visit during period of data collection were invited to take part in the study but those diabetic patients who had serious medical problem making interview difficult were excluded.

\subsection{Variables}

Presence or absence of suicidal plan was the outcome variables whereas independent variables include sociodemographic, clinical and substance related variables.

\subsection{Data Collection Procedures and Instruments}

Data was collected with the Amharic versions of questionnaires. Pre-test was also done 1 week before the main data collection on $21 \mathrm{DM}$ patients $(5 \%)$ of sample size at Abaymado Hospital, a hospital located about $5 \mathrm{~km}$ away from the study area. Three BSc nurses were involved in the data collection. The data collectors and supervisors were given short term training about study aims, procedures, and ethical issues and data quality control methods. Suicidal plan was assessed using suicide manual of composite international diagnostic interview (CIDI). Level of adherence to diabetic medication was assessed as poor, medium and high adherence using morrisk- 8 medication adherence scale. Pooradherence was defined as a score of less than 6 , medium adherence with score of 6-7 and high adherence with score of 8 [26, 29]. Social support was assed using oslow-3 item social support scale. Poor social support, moderate social support and good social support were defined at cut-off point 3-8, 9-11 and 12-14 points [30].

\subsection{Data Processing and Analysis}

Epi-info version 7 was used as data entry tool and Statistical Packages for Social Sciences, version 20 (SPSS-20) had been utilized to analyze the data after it was exported from Epi-info. Frequency, mean, median, standard deviation and crosstabs were the descriptive statistical measures employed in summarizing outcome and independent variables. A logistic regression model was fitted to identify risk factors for depression and suicidal plan.

A p-value $<0.25$ in bivariate analysis was used as fitting criteria into multivariable logistic regression. An Odds ratio with 95\%CI had been employed to show association strength and a p-value of $<0.05$ in multivariable logistic regression was statistically declared as significant.

\subsection{Ethical Considerations}

Ethical clearance letter was obtained from ethical institutional review board of university of Gondar, college of medicine and health science and ethical committee of AMSH. Permission letter was received from Felegehiwot referral hospital, informed consent was taken verbally from each study participant after explanation about aim of the study had been provided. Participation was voluntary and information was collected anonymously. 
Participants with current suicidal plan were fully evaluated by the principal investigator and linked to psychiatry clinic for further assessment and treatment.

\section{Results}

\subsection{Background Characteristics of Participants}

The response rate for this particular study was 421 (99.5\%). The average age $( \pm$ SD) of participants was $38.0( \pm 13.9)$ years. Among respondents two hundred twenty seven (53.9\%), three hundred fifty three $(83.6 \%)$, two hundred fifty six $(60.8 \%)$, one hundred ninety two $(45.6 \%)$ and one hundred ninety six (46.6\%) were males, orthodox, married, noneducated and farmers respectively (Table 1).

Table 1. Distribution of diabetic patients by their socio-demographic characteristics at Felegehiwot referral hospital diabetic clinic $(n=421)$, 2017

\begin{tabular}{|c|c|c|c|}
\hline \multirow{2}{*}{\multicolumn{2}{|c|}{ Characteristics }} & \multicolumn{2}{|c|}{ Suicidal plan, n (\%) } \\
\hline & & \multirow{2}{*}{$\begin{array}{l}\text { Yes } \\
21(9.3)\end{array}$} & \multirow{2}{*}{$\begin{array}{l}\text { No } \\
206(90.7)\end{array}$} \\
\hline Sex & Male & & \\
\hline sex & Female & $24(12.4)$ & $170(87.6)$ \\
\hline \multirow{5}{*}{ Age } & $18-24$ & $10(13.5)$ & $64(86.5)$ \\
\hline & $25-34$ & $17(14.6)$ & $99(85.4)$ \\
\hline & $35-44$ & $8(8.3)$ & $89(91.7)$ \\
\hline & $45-54$ & $8(10.4)$ & $69(89.6)$ \\
\hline & 55 and above & $2(3.5)$ & $55(96.5)$ \\
\hline \multirow{3}{*}{$\begin{array}{l}\text { Marital } \\
\text { status }\end{array}$} & Married & $28(10.9)$ & $228(89.1)$ \\
\hline & Single & $7(7.5)$ & $86(82.5)$ \\
\hline & Divorced/separated/widowed & $10(13.9)$ & $62(86.1)$ \\
\hline \multirow{4}{*}{ Education } & Have no formal education & $20(10.4)$ & $172(89.6)$ \\
\hline & Grade $1-8$ & $14(15)$ & $79(85)$ \\
\hline & Grade 9-12 & $7(12)$ & $51(88)$ \\
\hline & Diploma and above & $4(5)$ & $74(95)$ \\
\hline \multirow{5}{*}{ Occupation } & Employed & $14(10.8)$ & $115(89.2)$ \\
\hline & Unemployed & $2(7)$ & $26(93)$ \\
\hline & Farmer & $19(9.7)$ & $177(90.3)$ \\
\hline & Student & $3(11.5)$ & $23(88.5)$ \\
\hline & Others & $7(16.7)$ & $35(83.3)$ \\
\hline \multirow{3}{*}{$\begin{array}{l}\text { Social } \\
\text { support }\end{array}$} & Poor & $32(13.2)$ & $210(86.8)$ \\
\hline & Moderate & $9(8)$ & $105(92)$ \\
\hline & Strong & $4(6)$ & $61(94)$ \\
\hline
\end{tabular}

\subsection{Clinical and Substance use Characteristics of the Respondents}

Three hundred sixty three $(86 \%)$ and $56(14 \%)$ of participants were type-II and type-I DM patients respectively. One hundred eighty four $(43.7 \%)$ were on insulin therapy. Two hundred fifty seven $(61 \%)$ had been living with diabetes for $<5$ years. Fifty six $(13.3 \%)$ of participants had comorbid medical illness in addition to DM. One hundred thirty-six $(32.3 \%)$ of the respondents had a history of substance use within the past three months before data collection time. Among these; the majority, $123(90.5 \%)$ reported that they were using alcohol and $11(8 \%)$ of them were smoking a cigarette. The prevalence of suicidal plan among diabetes patients was found to be $10.7 \%(95 \% \mathrm{CI}$ : $7.80,13.90)$ (Table 2).
Table 2. Distribution of diabetic patients by their clinical and substance use characteristics at Felegehiwot referral hospital diabetic clinic $(n=421)$, 2017.

\begin{tabular}{|c|c|c|c|}
\hline \multirow{2}{*}{ Characteristics } & & \multicolumn{2}{|c|}{ Suicidal plan, n (\%) } \\
\hline & & Yes & No \\
\hline \multirow{2}{*}{ Type of DM } & Type 1 DM & $9(15.5)$ & $49(84.5)$ \\
\hline & Type 2 DM & $36(8.7)$ & $376(91.3)$ \\
\hline \multirow{3}{*}{$\begin{array}{l}\text { Current DM } \\
\text { medication }\end{array}$} & Insulin only & $25(13.6)$ & $159(86.4)$ \\
\hline & Insulin and oral agents & $5(8.8)$ & $52(91.2)$ \\
\hline & Hypoglycemic agents & $15(10)$ & $165(90)$ \\
\hline \multirow{3}{*}{$\begin{array}{l}\text { Medication } \\
\text { adherence }\end{array}$} & Low & $5(5.9)$ & $80(94.1)$ \\
\hline & Moderate & $18(10.8)$ & $149(89.2)$ \\
\hline & High & $22(13)$ & $147(87)$ \\
\hline \multirow{5}{*}{$\begin{array}{l}\text { Comorbid } \\
\text { medical illness }\end{array}$} & Hypertension & $5(11.4)$ & $39(88.6)$ \\
\hline & HIV & 0 & $4(100)$ \\
\hline & Ashma & 0 & $3(100)$ \\
\hline & Renal disease & 0 & $3(100)$ \\
\hline & $\begin{array}{l}\text { No-medical } \\
\text { comorbidity }\end{array}$ & $40(10.9)$ & $327(89.1)$ \\
\hline \multirow{2}{*}{$\begin{array}{l}\text { Chronicity of } \\
\text { DM }\end{array}$} & Less than 5 years & $27(10.5)$ & $230(89.5)$ \\
\hline & 5years and above & $18(10.9)$ & $146(89.1)$ \\
\hline \multirow{3}{*}{ BMI } & $<18.5 \mathrm{~kg} / \mathrm{m}^{2}$ & $5(12.5)$ & $35(87.5)$ \\
\hline & $18.5-24.5 \mathrm{~kg} / \mathrm{m}^{2}$ & $33(9.9)$ & $300(90.1)$ \\
\hline & $\geq 25 \mathrm{~kg} / \mathrm{m}^{2}$ & $7(14.6)$ & $41(85.5)$ \\
\hline \multirow{2}{*}{$\begin{array}{l}\text { Glycemic } \\
\text { control }\end{array}$} & Poor & $17(8.3)$ & $188(91.7)$ \\
\hline & Good & $28(12.9)$ & $188(87.1)$ \\
\hline \multirow{2}{*}{$\begin{array}{l}\text { Current } \\
\text { substance use }\end{array}$} & Yes & $15(11)$ & $121(89)$ \\
\hline & No & $30(10.5)$ & $255(89.5)$ \\
\hline
\end{tabular}

\subsection{Prevalence of Suicidal Plan Among Patients with Diabetes Mellitus}

The prevalence suicidal plan in this study was $10.7 \%$. Suicidal plan was lower among males $(9.25 \%)$ than females $(12.4 \%)$ but this difference is also not statistically significant $\left(\mathrm{X}^{2}=1.067, \mathrm{P}=0.344\right) .17(37.8 \%)$ participants with suicidal plan were in the age group of 25-34 years. Majority of participants with suicidal plan were also type $2 \mathrm{DM}$ patients $35(77.8 \%)$.

\subsection{Factors Associated with Suicidal Plan Among People with Diabetes Mellitus}

The results of multivariable logistic regression showed that being unemployed, poor medication adherence and current substance use were found to have a statistically significant association with suicidal plan in the multivariable binary regression model.

In the final model unemployment was found to be a determinant variable affecting suicidal plan. Unemployed participants $(\mathrm{AOR}=3.59,95 \% \mathrm{CI}: 1.25,10.89)$ were 3.6 times at higher risk to have suicidal plan as compared to employed respondents. Having poor medication adherence in multivariable logistic regression was 2.4 times $(\mathrm{AOR}=2.43$, $95 \%$ CI: $1.83,8.15$ ) more risky for suicidal plan as compared to respondents with high medication adherence and current use of substance increase the risk of suicidal plan by almost 2 times $(\mathrm{AOR}=1.82,95 \% \mathrm{CI}: 1.45,4.24)$ as compared to respondents who are not currently using substance (Table 3 ). 
Table 3. Factors associated with suicidal plan among diabetic patients at Felegehiwot Referral hospital, Bahir-Dar, Ethiopia, 2017 (n=421).

\begin{tabular}{|c|c|c|c|c|}
\hline \multirow{2}{*}{ Explanatory variable } & \multicolumn{2}{|c|}{ Suicidal plan } & \multirow{2}{*}{ COR $(95 \% \mathrm{CI})$} & \multirow{2}{*}{ AOR (95\% CI) } \\
\hline & Yes & No & & \\
\hline \multicolumn{5}{|l|}{ Sex } \\
\hline Male & 21 & 206 & 1.00 & 1.00 \\
\hline Female & 24 & 170 & $0.72(1.02,1.34)$ & $0.9(0.46,1.78)$ \\
\hline \multicolumn{5}{|l|}{ Occupational status } \\
\hline Employed & 14 & 115 & 1.00 & 1.00 \\
\hline Unemployed & 2 & 26 & $1.58(1.22,7.39)$ & $3.59(1.25,10.89)^{*}$ \\
\hline Farmer & 19 & 177 & $1.13(0.55,2.35)$ & $5.44(0.91,32.62)$ \\
\hline Student & 3 & 23 & $0.93(0.25,3.51)$ & $2.06(0.56,7.63)$ \\
\hline Others & 7 & 35 & $0.60(0.23,1.63)$ & $3.36(0.53,22.68)$ \\
\hline \multicolumn{5}{|l|}{ Medication adherence } \\
\hline Poor & 5 & 80 & $2.34(1.67,6.56)$ & $2.43(1.83,8.15)^{*}$ \\
\hline Intermediate & 18 & 149 & $1.24(0.64,2.40)$ & $1.41(0.68,2.91)$ \\
\hline High & 22 & 147 & 1.00 & 1.00 \\
\hline \multicolumn{5}{|l|}{ Type of DM } \\
\hline Type 1 DM & 9 & 49 & $0.59(0.27,1.32)$ & $0.57(0.23,1.38)$ \\
\hline Type 2 DM & 36 & 327 & 1.00 & 1.00 \\
\hline \multicolumn{5}{|l|}{ Current substance use } \\
\hline Yes & 15 & 121 & $1.25(0.09,2.85)$ & $1.82(1.45,4.24)^{*}$ \\
\hline No & 30 & 255 & 1.00 & 1.00 \\
\hline \multicolumn{5}{|l|}{ Social support } \\
\hline Poor & 32 & 210 & $0.43(0.12,1.26)$ & $0.44(0.54,1.35)$ \\
\hline Moderate & 9 & 105 & $0.76(0.23,2.59)$ & $0.67(0.19,2.42)$ \\
\hline Strong & 4 & 61 & 1.00 & 1.00 \\
\hline
\end{tabular}

*p-value $<0.05$, Model chi-square $=9.309, \mathrm{df}=8$ and $\mathrm{p}$-value $=0.317$.

\section{Discussion}

The prevalence of suicidal plan in this study was $10.7 \%$ respectively. Being unemployed and poor medication adherence and current substance use were found to have a statistically significant association with suicidal plan.

Suicidal plan was found among $10.7 \%$ of study participants in this study. This was in line with findings from USA studies $13.5 \%$ and $10 \%(9,10)$ but lower as compared to results from an observational [22] and cross-sectional [15] studies in USA $(26,4 \%$ and $15 \%)$ respectively. However, it was higher than the result of previous studies from USA (6.3\%) (19) and Nigeria (6.3\%) [31]. Difference in prevalence could be attributed to variation in sample size, study design and study subjects. 91 and 190 diabetes mellitus patients were included in studies which yields higher result. Study designs were also prospective cohort [19] and case control [9] and mini-international neuropsychiatric interview was used in Nigerian study. Study population was type 1 diabetes patients in most of previous studies but both diabetes types in current study.

Being unemployed were nearly 2 times higher risk for suicidal plan as compared to participants employed. This was in agreement with two studies in USA in which unemployment was a risk factor for suicidal plan $[9,32,33]$. Unemployment in addition to diabetes will be considered as burdensome by diabetic patients, and this can affect the patients' quality of life negatively and might contribute suicidal plan. Noncompliance to medication was a risk factor for suicidal plan in this study, which was 2.4 times higher risk to have suicidal plan as compared to participants who have good compliance to their medication. This finding was also supported by study findings from USA [19, 22].

Use of substance in past 3 months of data collection period increase the risk of suicidal plan by almost 2 times as compared to respondents who were not using substance in past three months before data collection period which is similar with finding from two studies [9, 34, 35]. This might be due to the CNS depressant effect of drugs like alcohol and low serotonin level which had a potential to induce impulsive behavior like suicidal tendency [36] and continuous substance use itself could be considered as chronic suicide [37].

Limitations for this study include cross-sectional nature of study design makes it difficult to establish causality between depression, suicidal plan and the associated factors identified for these outcome variables. In addition since the study was conducted in one institution, its finding is might not be generalizable to other institutions providing treatment for diabetes mellitus patients in Ethiopia. Besides this recall bias and social desirability bias as data was collected by interviewer administered questionnaires should be taken in to consideration.

\section{Conclusion}

Findings of this study revealed that suicidal plan among diabetic patients were high. Being unemployed from sociodemographic variables, poor medication adherence from clinical variables and current substance use from substance related variables were risk factors for suicidal plan. Early screening and treatment of diabetic patients has to be a routine activity to be conducted in the diabetic clinics. 


\section{Abbreviations}

AOR: Adjusted Odds Ratio, BMI: Body Mass Index, CI: Confidence Interval, CIDI: Composite International Diagnostic Interview, COR: Crude Odds Ratio, CSA: Central Statistical Agency, DF: Degree of Freedom, DM: Diabetes Mellitus, OR: Odds Ratio, PHQ-9: Patient Health Questionnaire-9, SD: Standard Deviation, SPSS: Statistical Package for Social Science, Type 1 DM: Type 1 Diabetes Mellitus, Type 2 DM: Type 2 Diabetes Mellitus, USA United States of America.

\section{Declarations}

\section{Ethics Approval and Consent to Participate}

Letter of ethical approval was obtained from the ethical Review Board of UOG and ethical committee of AMSH. In addition permission letter was obtained from the study area. Participants were clearly informed of the aims of the study and verbal consent had been taken from individual participants before the interview began.

\section{Consent for Publication}

Not Applicable

\section{Availability of Data and Materials}

The datasets used throughout this research process are available from the corresponding authors on reasonable request.

\section{Funding}

There was a shortage of funds for over all research work.

\section{Authors' Contributions}

$\mathrm{MN}$ was the principal investigator designing and doing the analysis. $\mathrm{MN}$ and $\mathrm{AB}$ involved in manuscript preparation and ratified the manuscript.

\section{Acknowledgements}

We authors were grateful to express our thanks to Gondar University College of medicine and health science \& Felegehiwot referral hospital for all forms of help provided. Besides, we would like to thank the participants, data collectors and supervisors for being a part and active involvement in the study process.

\section{References}

[1] Roupa Z, Koulouri A, Sotiropoulou P, Makrinika E, Marneras $\mathrm{X}$, Lahana I, et al. Anxiety and depression in patients with type 2 diabetes mellitus, depending on sex and body mass index. Health Sci J. 2009; 3 (1): 32-40.

[2] Harrison TA, Hindorff LA, Kim H, Wines RC, Bowen DJ, McGrath BB, et al. Family history of diabetes as a potential public health tool. American journal of preventive medicine. 2003; 24 (2): 152-9.

[3] Guariguata L, Whiting DR, Hambleton I, Beagley J, Linnenkamp U, Shaw JE. Global estimates of diabetes prevalence for 2013 and projections for 2035. Diabetes research and clinical practice. 2014; 103 (2): 137-49.

[4] Kruse J, Schmitz N, Thefeld W. On the association between diabetes and mental disorders in a community sample: results from the German National Health Interview and Examination Survey. Diabetes care. 2003; 26 (6): 1841-6.

[5] Chew B-H, Vos R, Mohd-Sidik S, Rutten GE. Diabetes-related distress, depression and distress-depression among adults with type 2 diabetes mellitus in Malaysia. PloS one. 2016; 11 (3): e0152095.

[6] Chaudhry R, Mishra P, Mishra J, Parminder S, Mishra B. Psychiatric morbidity among diabetic patients: A hospitalbased study. Industrial psychiatry journal. 2010; 19 (1): 47.

[7] de Ornelas Maia ACC, de Azevedo Braga A, Brouwers A, Nardi AE, e Silva ACdO. Prevalence of psychiatric disorders in patients with diabetes types 1 and 2 . Comprehensive psychiatry. 2012; 53 (8): 1169-73.

[8] Apter A. Suicide and suicidal behavior. Public health reviews. 2012; 34 (2): 1.

[9] Roy A, Roy M, Janal M. Suicide attempts and ideation in African-American type 1 diabetic patients. Psychiatry research. 2010; 179 (1): 53-6.

[10] Myers AK, Grannemann BD, Lingvay I, Trivedi MH. Brief report: depression and history of suicide attempts in adults with new-onset Type 2 Diabetes. Psychoneuroendocrinology. 2013; 38 (11): 2810-4.

[11] Pompili M, Lester D, Innamorati M, De Pisa E, Amore M, Ferrara C, et al. Quality of life and suicide risk in patients with diabetes mellitus. Psychosomatics. 2009; 50 (1): 16-23.

[12] Löfman S, Hakko H, Mainio A, Timonen M, Räsänen P. Characteristics of suicide among diabetes patients: a population based study of suicide victims in Northern Finland. Journal of psychosomatic research. 2012; 73 (4): 268-71.

[13] Brownlee C. Depression and Diabetes Are Fellow Travelers, Researchers Say. The JHU Gazette. 2008; 37 (40): 1-2.

[14] Ali S, Stone M, Peters J, Davies M, Khunti K. The prevalence of co - morbid depression in adults with Type 2 diabetes: a systematic review and meta - analysis. Diabetic Medicine. 2006; 23 (11): 1165-73.

[15] Fuller-Thomson E, Sawyer J-L. Lifetime prevalence of suicidal ideation in a representative sample of Canadians with type 1 diabetes. Diabetes research and clinical practice. 2009; 83 (1): e9-e11.

[16] Organization WH. Preventing suicide: a global imperative: World Health Organization; 2014.

[17] Mars B, Burrows S, Hjelmeland H, Gunnell D. Suicidal behaviour across the African continent: a review of the literature. BMC Public Health. 2014; 14 (1): 606.

[18] Fekadu A, Medhin G, Selamu M, Shiferaw T, Hailemariam M, Rathod SD, et al. Non-fatal suicidal behaviour in rural Ethiopia: a cross-sectional facility-and population-based study. BMC psychiatry. 2016; 16 (1): 75. 
[19] Goldston DB, Kovacs M, Ho VY, Parrone PL, Stiffler L. Suicidal ideation and suicide attempts among youth with insulin-dependent diabetes mellitus. Journal of the American Academy of Child \& Adolescent Psychiatry. 1994; 33 (2): 240-6.

[20] Goodwin RD, Kroenke K, Hoven CW, Spitzer RL. Major depression, physical illness, and suicidal ideation in primary care. Psychosomatic Medicine. 2003; 65 (4): 501-5.

[21] Han SJ, Kim HJ, Choi YJ, Lee KW, Kim DJ. Increased risk of suicidal ideation in Korean adults with both diabetes and depression. Diabetes research and clinical practice. 2013; 101 (3): e14-e7.

[22] Goldston DB, Kelley AE, Reboussin DM, Daniel SS, Smith JA, Schwartz RP, et al. Suicidal ideation and behavior and noncompliance with the medical regimen among diabetic adolescents. Journal of the American Academy of Child \& Adolescent Psychiatry. 1997; 36 (11): 1528-36.

[23] Parra-Uribe I, Blasco-Fontecilla H. Risk of re-attempts and suicide death after a suicide attempt: A survival analysis. 2017; 17 (1): 163.

[24] Turecki G, Brent DA. Suicide and suicidal behaviour. Lancet. 2016; 387 (10024): 1227-39.

[25] Walle F, Kebede N, Tsegaye A, Kassa T. Seroprevalence and risk factors for Toxoplasmosis in HIV infected and noninfected individuals in Bahir Dar, Northwest Ethiopia. Parasites \& vectors. 2013; 6 (1): 15.

[26] Al-Qazaz HK, Hassali MA, Shafie AA, Sulaiman SA, Sundram S, Morisky DE. The eight-item Morisky Medication Adherence Scale MMAS: translation and validation of the Malaysian version. Diabetes research and clinical practice. 2010; 90 (2): 216-21.

[27] Abebe SM, Berhane Y, Worku A. Barriers to diabetes medication adherence in North West Ethiopia. SpringerPlus. 2014; 3 (1): 195.

[28] Abebe SM, Berhane Y, Worku A, Alemu S, Mesfin N. Level of sustained glycemic control and associated factors among patients with diabetes mellitus in Ethiopia: a hospital-based cross-sectional study. Diabetes, metabolic syndrome and obesity: targets and therapy. 2015; 8: 65.

[29] de Oliveira-Filho AD, Morisky DE, Neves SJF, Costa FA, de Lyra DP. The 8-item Morisky Medication Adherence Scale: validation of a Brazilian-Portuguese version in hypertensive adults. Research in Social and Administrative Pharmacy. 2014; 10 (3): 554-61.

[30] Abiola T, Udofia O, Zakari M. Psychometric properties of the 3-item oslo social support scale among clinical students of Bayero University Kano, Nigeria. Malaysian Journal of Psychiatry. 2013; 22 (2): 32-41.

[31] Igwe M, Uwakwe R, Ahanotu C, Onyeama G, Bakare M, Ndukuba A. Factors associated with depression and suicide among patients with diabetes mellitus and essential hypertension in a Nigerian teaching hospital. African health sciences. 2013; 13 (1): 68-77.

[32] Goodwin RD, Marusic A, Hoven CW. Diabetes and suicidal ideation among youth in the community. Archives of pediatrics \& adolescent medicine. 2002; 156 (8): 841.

[33] Druss B, Pincus H. Suicidal ideation and suicide attempts in general medical illnesses. Archives of internal medicine. 2000; 160 (10): 1522-6.

[34] Radobuljac MD, Bratina NU, Battelino T, Tomori M. Lifetime prevalence of suicidal and self-injurious behaviors in a representative cohort of Slovenian adolescents with type 1 diabetes. Pediatric diabetes. 2009; 10 (7): 424-31.

[35] Pompili M, Forte A, Lester D, Erbuto D, Rovedi F, Innamorati M, et al. Suicide risk in type 1 diabetes mellitus: a systematic review. Journal of psychosomatic research. 2014; 76 (5): 35260.

[36] Kamali M, Oquendo MA, Mann JJ. Understanding the neurobiology of suicidal behavior. Depression and anxiety. 2001; 14 (3): 164-76.

[37] Menninger KA. Man against himself. Psychohistory Review. 1985. 